\title{
A NOITE COMO PRODUTO TURÍSTICO A INTEGRAR NO PLANEAMENTO URBANO
}

DIANA ALMEIDA ${ }^{1}$

JOÃO FUMEGA ${ }^{2}$

TERESA ALVES ${ }^{1}$

\begin{abstract}
Resumo - A iluminação artificial, associada a importantes mudanças económico-sociais, conferiram à noite novos usos e novas paisagens, que influenciaram fortemente a forma urbana e os modos de intervir no território. As cidades, pela representatividade populacional e produção económica e cultural, são os locais em que o espaço-tempo da noite sofreu mais transformações. Têm sido várias as perspectivas teóricas que abordam esta problemática, desde o ponto de vista da criminalidade, insegurança, alcoolismo, assim como perspectivas associadas à componente artística e de lazer. Será esta última perspectiva, aquela que irá ser tida em conta, como forma de consubstanciar a relação crescente entre o turismo e a noite. O objectivo central reside, assim, no estudo da importância das actividades de lazer como factor de atracção turística, para avaliar o potencial atractivo dos eventos ou actividades que decorrem à noite, como elementos fundamentais para a promoção da imagem da cidade e seu desenvolvimento.
\end{abstract}

Palavras-chave: Turismo, noite, planeamento, cidade, lazer.

\begin{abstract}
NigHTLIFE - A TOURISM PRODUCT TO BE INCLUDED IN URBAN PLANNING. Artificial light and important social and economic changes offered night new uses and new landscapes that had influenced territorial planning and the urban form. Cities are where the space-time night has suffered major transformations, due to its population density and economic and cultural production. The challenges of the night-time period have been approached from different points of view: crime issues, insecurity, alcohol disorderly behaviours, and others associated with leisure and artistic activities at night. These two last perspectives are the ones that are going to be analyzed, in order reinforce the growing relation between night and tourism. The main goal of this paper focuses the study of the nighttime leisure activities relevance and its role in the touristic attraction. Therefore, we intend
\end{abstract}

Recebido: Março 2011. Aceite: Julho 2011.

1 Núcleo TERRiTUR (Turismo, Cultura e Território), Centro de Estudos Geográficos, IGOT-UL; diana-almeida@campus.ul.pt; teresa.alves@campus.ul.pt

2 Núcleo MOPT (Modelação, Ordenamento e Planeamento do Território), Centro de Estudos Geográficos, IGOT-UL; joaofumega@gmail.com 
to evaluate the attractiveness of events and leisure activities that occur at night, as a crucial ingredient to promote cities image and contribute to its development.

Keywords: Tourism, night, planning, city, leisure.

Résumé - LA NUIT COMME PRODUIT TOURISTIQUE À INTÉGRER DANS LA PLANIFICATION URBAINE. L'éclairage artificiel, associé à d'importants changements économiques et sociaux, a engendré de nouvelles utilisations de la nuit et a fait naître de nouveaux paysages, qui ont fortement influencé la forme de la ville et les moyens d'intervenir sur le territoire. La ville est le lieu où l'espace-temps de la nuit a souffert le plus de transformations, de par sa densité de population et sa production économique et culturelle. Les enjeux de la période nocturne ont été abordés sous des angles différents : celui de la criminalité, de l'insécurité, de l'alcoolisme, et celui des perspectives associées à la composante artistique et de loisirs. C'est cette dernière perspective qui sera analysée, afin de confirmer la relation croissante entre le tourisme et la vie nocturne. L'objectif principal est, par conséquent, d'étudier l'importance des loisirs nocturnes et leur rôle dans l'attraction touristique. Ainsi, nous cherchons à évaluer l'attrait potentiel des événements et des activités qui ont lieu la nuit, ceux-ci étant des éléments essentiels à la promotion de l'image de la ville et à son développement.

Mots-clés: Tourisme, nuit, planification, ville, loisirs.

\section{INTRODUÇÃO}

A intenção de explorar a noite como elemento de desenvolvimento urbano, prende-se com a escassez deste tipo de estudos no âmbito do planeamento das cidades. Este facto levanta algumas questões quando se pensa nos tempos e nos usos urbanos, em que as sociedades tendem a exercer as suas diversas actividades a ritmos diferentes, denotando-se, em algumas cidades como Nova Iorque, Pequim ou Berlim (Alves, 2007a), o prolongamento das actividades tradicionalmente diurnas, pela noite dentro - as designadas cidades $24 / 7$, ou seja, cidades em contínuo vinte e quatro horas por dia, sete dias por semana (Gwiazidzinski, 2005).

As cidades são espaços privilegiados, com grandes potencialidades ao nível dos usos dos tempos de lazer, possibilitando a sua projecção mediática relativamente aos eventos nocturnos. Surgem questões como a segurança, a iluminação ou adequabilidade dos equipamentos, sendo por isso, não só importante perceber as potencialidades nocturnas de determinados território, os seus antecedentes, mas também quais as transformações necessárias para que a fruição do espaço público não tenha limites horários. A representatividade populacional, a produção económica, política e cultural das cidades fomentou nestas grandes alterações no que respeita ao espaço-tempo da noite. A dimensão nocturna dos espaços públicos passou a estar presente, quer por razões associadas à segurança e à criminalidade, quer pela disponibilidade da sociedade e da economia para o surgimento de vários segmentos de actividades de lazer que acontecem à noite. Esta última perspectiva foi a que mais interessou aos autores e consistiu no ponto de partida para a construção deste artigo. 
O objectivo central do estudo reside na importância das actividades de lazer à noite como factor de atracção turística. Pretende-se avaliar o potencial atractivo dos eventos ou actividades que decorrem à noite, como elementos fundamentais para a promoção da imagem da cidade e seu desenvolvimento.

Importa enquadrar a problemática da noite e abordar a evolução histórica, que originou o despoletar da noite como uma dimensão vivível dos espaços públicos urbanos. Foi a iluminação pública que permitiu esta passagem revolucionária entre o dia e a noite, problemática analisada no ponto 2.1. Na secção seguinte irão ser postas em evidência duas perspectivas essenciais na abordagem das questões da noite urbana: as visões antagónicas francófonas e anglo-saxónicas, que estudam a noite em dois aspectos fundamentais e complementares: por um lado as potencialidades da noite associadas à arte da luz e à valorização territorial pela iluminação, a cultura e as artes (francófona), e por outro lado, os estudos dos comportamentos socialmente desviantes, como o alcoolismo, a criminalidade e a insegurança (anglo-saxónica). Perante esta dualidade, interessa perceber qual o papel da noite no contexto do planeamento, como um espaço-tempo negligenciado, ao mesmo tempo que a noite se apresenta como elemento central no desenvolvimento urbano.

O terceiro ponto incidirá sobre o estudo das actividades de lazer como uma componente económica, cultural e social, indissociável do período nocturno, assim como os principais desafios que se colocam a estas actividades, bem como os impactos que estas têm no turismo e na imagem das cidades.

\section{NOITE: ENQUADRAMENTO TEÓRICO DA PROBLEMÁTICA}

\section{Evolução histórica: a iluminação como motor da afirmação do conceito de "espaço-tempo" da noite}

A iluminação pública começou a ser utilizada por volta do ano de 1900, como um meio para embelezar e decorar os principais monumentos e espaços públicos notáveis (Narboni, 2003). Apesar do investimento na iluminação, a noite continuava a representar um entrave para o desenvolvimento das actividades, tendencialmente diurnas - o dia e a noite pertenciam a duas realidades distintas, que não se juntavam nem se complementavam: o dia era o palco das actividades económicas, sociais, culturais etc., enquanto a noite estava associada ao desconhecido, provocando medo, mistério, curiosidade e simultaneamente seduzindo (Gwiazidzinski, 2003). Segundo Gwiazidzinski (2005), a noite estava recheada de contradições: correspondia, simultaneamente, ao período de recolhimento, em que se deveria estar em casa, a descansar e a dormir, respondendo às necessidades biológicas. Contudo, cada vez mais pessoas estavam a fazer uso do período nocturno para várias actividades, contrariando a tendência natural.

Antes da invenção da electricidade, a noite era um espaço-tempo reservado a poucas pessoas e actividades (Paquot, 2000). Era visto como um espaço de reclusão, 
de mistério, de descanso. As poucas actividades que se desenvolviam durante a noite estavam ligadas sobretudo à segurança, à vigília. A invenção da electricidade coincidiu com o período mais pujante da industrialização e gerou um novo paradigma, abrindo portas para novos usos: as fábricas podiam laborar mesmo quando o sol se punha, pois a iluminação artificial assim o permitia. A lógica de produção passou também a concentrar-se essencialmente no lucro e no crescimento económico. Da combinação destes dois factores resultou uma nova realidade, que ocupava um espaço temporal até então não aproveitado: a noite. A noção do "dia" associado ao período de trabalho transformou-se, e passou assim a ter o dobro das horas disponíveis para as demais actividades económicas, gerando novas formas de organização laboral, reformulando a própria estrutura social. De um modo geral, antes da invenção da electricidade e da iluminação eléctrica, quem saía à noite era uma minoria elitista, masculina, que frequentava os cafés de produção cultural e debate político e literário, sendo poucas as profissões às quais era exigido o trabalho nocturno. Embora tenha sido o trabalho da fábrica o impulsionador da difusão da categoria de trabalhador nocturno, não foi só no sector industrial que nasceram novas profissões, adaptadas a este novo horário. A iluminação artificial permitiu grandes mudanças na esfera profissional e da produção, aliando-se às mudanças sociais que estavam a emergir nas primeiras décadas do século XX.

Entre os motores da mudança social, podem-se salientar os seguintes: a liberalização das práticas sociais; as mudanças demográficas; o crescimento do número de pessoas sem limitações de tempo e livres de encargos/preocupações familiares; e o surgimento de novos padrões de vida urbanos, que contribuíram para a redução das diferenças entre o dia e a noite, ao mesmo tempo que vão surgindo diferentes ritmos de vida, à custa da divulgação e da utilização exponencial da luz artificial. De acordo com Alves (2007b), as práticas sociais relacionadas com o tempo livre, ganharam uma nova projecção no contexto social - o tempo livre emerge como um importante período de valorização pessoal. Estas transformações encontram-se relacionadas com as inovações tecnológicas na esfera da iluminação, que permitiram o prolongamento das actividades económicas, culturais e políticas pela noite dentro ou, simplesmente, permitiram que as pessoas reservassem mais tempo para si próprias (Espinasse et. al., 2005). As actividades de lazer, sobretudo desde o princípio do século XX, conheceram uma forte expansão. Essa expansão ocorreu não só na sua tipologia, no público alcançado, e mais tarde, também nas actividades ligadas ao comércio de consumíveis nocturnos. As actividades económicas reconheceram na noite um palco de expansão, tipificando os consumos e categorizando espaços urbanos privilegiados para esses consumos, associados ao género, idade, nível de instrução e estatuto socioeconómico dos potenciais consumidores da noite. Uma certa democratização do lazer, patente na organização social e laboral, favoreceu o crescimento de um grupo de actividades associadas a experiências na noite, contribuindo assim para o desenvolvimento de novos segmentos económicos, que estão activos apenas durante a noite (Cauquelin, 1977; Gwiazidzinski, 2003). 
Após a Segunda Guerra Mundial, as inovações tecnológicas associadas com a produção e distribuição da luz, permitiram a diminuição dos preços da electricidade, tornando possível o conjunto de mudanças mencionadas. Simultaneamente, as transformações na esfera da política e no planeamento das cidades e da luz, tornou igualmente possíveis essas mudanças (Narboni, 2003).

Como afirma Alves (2010), a iluminação pública começou a difundir-se como um bem essencial, mais do que uma maneira de obter lucros por parte das empresas. Até aos anos sessenta, a colocação da iluminação pública era feita sem planeamento, e sem estar inserida numa estratégia para a cidade (Narboni, 2003). O principal objectivo residia em iluminar ruas, avenidas ou praças, ao mesmo tempo que os monumentos mais importantes eram também postos em evidência através da luz - pretendia-se que as pessoas conseguissem ver, e ser vistas. Estas opções funcionavam no sentido de revelar objectos, formas ou caminhos, criando a sensação de conforto, contribuindo igualmente para a compreensão da noite urbana (Alves, 2008). De início, segundo Narboni (2003), as intervenções na esfera da iluminação estavam limitadas à escolha das lâmpadas e do tipo de candeeiros. Como a oferta era limitada, de certa forma, as paisagens nocturnas tendiam para a estandardização, sem respeito pela diversidade, nem pelo espírito do lugar. Esta padronização prendia-se também com a ausência da necessidade de distinguir usos nos espaços públicos, até porque a noite era ainda considerada espaço privado, de vivência caseira.

Com a afirmação da globalização, da economia a uma escala global, a noite conheceu uma expansão significativa. O espaço-tempo da noite deixou de ser fundamentalmente dos artistas, dos boémios, ou de alguns trabalhadores desqualificados. Com o crescimento da economia mundial, a expansão da classe média e, também, a maior taxa de literacia resultante do aumento dos níveis de educação, o período da noite passou do quotidiano de um conjunto reduzido de pessoas, para um período largamente difundido pela população, usado para a realização de diversas actividades: trabalhar, estudar, recreio e lazer, desporto, saúde, ou compras. Actividades ligadas à banca, transportes, prestação de serviços de apoio ao cliente, entre outras, passaram a funcionar 24 horas por dia, não só devido aos diferentes fusos horários, mas também para acomodar necessidades crescentes de clientes que funcionam em contínuo entre dia e noite. No caso português, esta situação é mais visível nas superfícies comerciais, que fecham cada vez mais tarde, aliadas às actividades de lazer que, cada vez mais, se processam durante a noite. Quer sejam concertos de música, sessões de cinema, bares, mas também actividades que até então funcionavam predominantemente durante o dia, como museus, exposições, entre outros, cada vez mais elas tendem a estar abertas a um público que sai à noite e que usa este espaço-tempo para se divertir ou descontrair. Sem a iluminação pública artificial, nenhuma destas situações (agora comuns) podia ter-se desenvolvido. A crescente presença da iluminação artificial nas cidades atribui à noite uma nova projecção no contexto urbano (Alves, 2008).

O conceito de "espaço-tempo" da noite advém, assim, precisamente da duplicidade que está encerrada no período nocturno. Por um lado, este é um tempo que se 
inicia com o pôr-do-sol, e que finda com o nascer do sol mas, por outro lado, a noite é simultaneamente um espaço, no sentido territorial e espacial, onde determinadas práticas, actividades, usos etc., ocorrem preferencialmente. Por esta razão a noite é muitas vezes designada como o "espaço-tempo" da noite, "l'espace-temps de nuit" referenciado por vários autores franceses, como Cauquelin, 1977 ou Gwiazidzinski, 2003, 2005, com o intuito de incorporar numa só palavra a multiplicidade de tempos e de espaços que a noite pode conter.

\section{A noite como elemento central no desenvolvimento urbano}

\subsection{A iluminação e segurança como factores determinantes nas políticas urbanas}

Os estudos primordiais de iluminação reflectiram a necessidade de hierarquizar a iluminação pública urbana, subdividindo por graus de relevância, as áreas que deveriam ser privilegiadas pela luz. O objectivo consistia em diferenciar e estabelecer tipologias de iluminação, de acordo com as características e o uso principal das vias de comunicação. A partir deste momento, emergem avanços importantes que permitiram diferenciar, à noite, os eixos pedonais dos eixos motorizados - a luz passou a ser, então, um instrumento que poderia ser usado no planeamento urbano (Alves, 2010).

A cidade francesa de Lyon é uma das cidades europeias que mais tem evoluído no campo do planeamento da iluminação. O primeiro Plano de Luz de Lyon teve início em 1989, e transformou por completo a imagem desta cidade. Este projecto pioneiro em termos políticos, técnicos e artísticos contou com a iluminação de mais de 250 ruas da cidade, excluindo objectivos meramente de segurança. O Plano de Luz de Lyon passou a fazer assim parte do planeamento urbano e da própria paisagem da cidade - em 2004 a revisão do primeiro plano deu origem a um segundo plano, onde a iluminação encontrou um lugar na criatividade, adaptando-se aos ritmos da cidade, aos contornos dos edifícios e da topografia, "Recognized as a distinct art and a profession, urban lighting has become an essential factor in the international impact of Lyon and its suburbs." (Fête dês Lumieres, http://www.lumieres. lyon.fr/lumieres/sections/en/lyon_and_light/lyon_the_city_specializing_in_ligh). Estes contributos permitiram a melhoria considerável da vida urbana, tornando Lyon um marco importante nas festas de luz, bem como na inovação artística, profissional e académica.

Como está especificado no site oficial da cidade de Lyon (Fête dês Lumieres, http://www.lyon.fr/vdl/sections/fr/urbanisme/plan_lumiere_1/le_nouveau_plan_ lumi8409), este novo plano de luz, com uma visão multifacetada, centra-se no território urbano e na iluminação diversificada dos bairros. A necessidade de encontro entre o homem e as suas actividades é acompanhada pela proposta de criação de ambiências variadas, que se focam em áreas concretas da cidade, por exemplo "Lyon Confluence: Schéma des principles de mise en lumière”. 
Sob o efeito da iluminação artificial os territórios transfiguram-se dando origem a paisagens nocturnas que são, em geral, muito diferentes das diurnas. A iluminação artificial põe em evidência certos aspectos do território, que durante o dia não são visíveis “( ...) good lighting, illuminates, clarifies, stimulates. Bad lighting, (...) dazzles, confuses and produces weariness" (Portela, 2007:113). À noite, nas áreas densamente povoadas, como as áreas urbanas, a grande preocupação centra-se nos quantitativos de luz essenciais, que permitam a continuação das diversas actividades pela noite dentro, mas também porque, tendencialmente a luz é sinónimo de segurança. Crê-se que um local é tanto mais seguro, quanto mais iluminado estiver, porque o espaço-tempo da noite é igualmente conotado com comportamentos desviantes (Alves e Almeida, 2009).

As questões relacionadas com a segurança constituem a componente da noite que tem sido mais estudada (Talbot, 2007; Helms, 2008). Não existem dados que a ssociem directamente noite e criminalidade, mas o que é certo é que há uma forte associação entre noite e insegurança (quadro 1) porque a falta de luz natural tem implicações sobre os modos como as pessoas se sentem e se comportam - a escuridão perturba e torna as pessoas mais sensíveis e vulneráveis (Alves e Almeida, 2009).

Quadro I - Grau de concordância com afirmações relacionadas com a iluminação e a segurança. Table I-Level of agreement related to lighting and security statements.

\begin{tabular}{|c|c|c|c|c|c|}
\hline \multirow[b]{2}{*}{$\begin{array}{l}\text { Considerando as seguintes afirmações, } \\
\text { indique o grau de concordância com: }\end{array}$} & \multicolumn{5}{|c|}{$\%$} \\
\hline & $\begin{array}{l}\text { Não } \\
\text { concordo }\end{array}$ & $\begin{array}{l}\text { Concordo } \\
\text { parcialmente }\end{array}$ & Concordo & $\begin{array}{l}\text { Concordo } \\
\text { plenamente }\end{array}$ & $\begin{array}{l}\text { Nunca pensei } \\
\text { no assunto }\end{array}$ \\
\hline $\begin{array}{l}\text { "À noite há menos segurança do que de } \\
\text { dia." }\end{array}$ & 12,5 & 35,0 & 30,0 & 15,0 & 0,0 \\
\hline $\begin{array}{l}\text { "Hoje à noite há menos segurança do que } \\
\text { no passado." }\end{array}$ & 12,5 & 17,5 & 45,0 & 22,5 & 0,0 \\
\hline $\begin{array}{l}\text { "A segurança dos espaços públicos à noite } \\
\text { depende da quantidade de luz da } \\
\text { iluminação." }\end{array}$ & 15,0 & 27,5 & 40,0 & 12,5 & 0,0 \\
\hline $\begin{array}{l}\text { "A segurança dos espaços públicos à noite } \\
\text { depende da qualidade da iluminação." }\end{array}$ & 17,5 & 25,0 & 32,5 & 17,5 & 5,0 \\
\hline $\begin{array}{l}\text { "A qualidade da luz nos espaços públicos } \\
\text { depende, acima de tudo, da quantidade de } \\
\text { luz da iluminação." }\end{array}$ & 27,5 & 25,0 & 27,5 & 12,5 & 5,0 \\
\hline $\begin{array}{l}\text { "Se um determinado percurso tem pouca } \\
\text { iluminação, procuro escolher um percurso } \\
\text { alternativo com mais iluminação." }\end{array}$ & 15,0 & 22,5 & 20,0 & 37,5 & 2,5 \\
\hline $\begin{array}{l}\text { "A segurança dos espaços públicos à noite } \\
\text { depende da quantidade de polícias." }\end{array}$ & 15,0 & 40,0 & 25,0 & 17,5 & 0,0 \\
\hline
\end{tabular}

Fonte: Inquéritos do Projecto NOITe, Tondela e Caldas da Rainha, 2009

Estas razões levam a que a luz artificial emerja como um poderoso instrumento, capaz de redesenhar e organizar os espaços, oferecendo visibilidade e dando protec- 
ção. À medida que aumenta a quantidade de luz colocada no espaço público aumenta a percepção de segurança (quadro I). Ou seja, quanto mais iluminado é um determinado espaço ou percurso, maior segurança é transmitida às pessoas que o frequentam ou atravessam, pois através da luz artificial é permitido o conhecimento e o domínio do espaço iluminado - através da capacidade de transmitir a informação desejada, utilizando uma iluminação apropriada, é possível atingir-se segurança e conforto, essenciais à vivência dos espaços públicos. Dados de um inquérito realizado em Tondela e Caldas da Rainha mostram que a larga maioria dos inquiridos "concordam" ou "concordam plenamente" com afirmações que reflectem este tipo de percepção (quadro I). O medo tende a aparecer, na mesma medida em que a luz diminui. Por essa razão, a iluminação artificial, cria nas pessoas o sentimento de segurança e domínio do território em termos visuais. Porém, a quantidade de luz nem sempre é sinónimo da qualidade da iluminação, como explicita Mizon (2002): se tivermos um foco de luz directamente apontado para o campo visual, pode ser bastante desorientador e até impedir a visualização (encadeamento).

A iluminação artificial afigura-se, assim, como um elemento-chave para o planeamento e os usos dos espaços públicos à noite, desempenhando um papel crucial no projecto urbano. Planear a iluminação significa estabelecer guias para o design, a orientação das luminárias, as intensidades e tipos de luz, ao mesmo tempo que se assegura a eficiência energética, originando qualidade de vida em termos de segurança, minimizando riscos ambientais e fomentando uma oportunidade de apreciar o céu nocturno. Os projectos de iluminação podem ter um papel estratégico na transformação ou na construção de novas paisagens nocturnas através de: i) melhorar os espaços, criando ambientes de maior qualidade, dando maior segurança; ii) revelar monumentos notáveis do património edificado que se transformam em referenciais na paisagem; iii) salientar detalhes, materiais, pormenores e oferecendo uma percepção mais clara da materialidade, enriquecendo a paisagem nocturna com informações não perceptíveis à luz do dia; iv) dar vida aos espaços públicos pela criação de condições para uma utilização nocturna, estimulando o convívio e a interacção social (Alves, 2008).

O entendimento da noite urbana está longe de ser totalmente absorvido pelos decisores políticos e pelos planeadores, mas a evolução da abordagem deste espaço-tempo com características tão particulares, tem vindo a desenvolver-se, ganhando espaço em documentos orientadores. Por exemplo, com base num estudo que decorreu no âmbito do Projecto NOITe (PTDC/GEO/64240/2006), realizado junto das Câmaras Municipais de Portugal Continental e Regiões Autónomas, é possível verificar que um número significativo inclui preocupações com as questões da iluminação e com a animação nocturna nas suas figuras de plano vigentes, como os Planos Directores Municipais ou Planos de Pormenor. No entanto, vê-se no quadro II (excerto exemplificativo de alguns resultados), que muito poucas dispõem de um plano de luz ou de eficiência energética. A própria qualidade da iluminação é maioritariamente considerada suficiente, sendo apontados problemas de cobertura e de sustentabilidade. 
Quadro II - Análise das respostas das Câmaras Municipais no domínio da iluminação.

Table II - Analysis of Municipality council responses regarding to local lighting issues.

\begin{tabular}{|c|c|c|c|c|c|}
\hline \multirow{2}{*}{ Dimensão } & \multicolumn{5}{|c|}{ Respostas de Câmaras Municipais (amostra) } \\
\hline & Porto & Águeda & Madalena (Açores) & Tavira & Vidigueira \\
\hline $\begin{array}{l}\text { Despesas com } \\
\text { iluminação pública } \\
\text { em } \% \text { do orçamento }\end{array}$ & $1,3 \%$ & $1,1 \%$ & $0,4 \%$ & $2,3 \%$ & - \\
\hline $\begin{array}{l}\text { Cobertura territorial } \\
\text { e população servida } \\
\text { por iluminação } \\
\text { pública (\%) }\end{array}$ & $\begin{array}{l}\text { Cobertura } \\
\text { total }-32.900 \\
\text { focos de } \\
\text { iluminação } \\
\text { pública }\end{array}$ & s/conh. & s/conh. & $\begin{array}{l}12 \% \text { da população } \\
\text { é servida pela } \\
\text { iluminação } \\
\text { municipal; a } \\
\text { restante é servida } \\
\text { pela rede nacional } \\
\text { (EDP) }\end{array}$ & - \\
\hline $\begin{array}{l}\text { Existência de planos } \\
\text { de eficiência } \\
\text { energética no } \\
\text { concelho }\end{array}$ & $\begin{array}{c}\text { Planos de } \\
\text { eficiência } \\
\text { energética } \\
\text { aplicados às vias } \\
\text { de comunicação. }\end{array}$ & $\begin{array}{c}\text { A Câmara } \\
\text { Municipal está a } \\
\text { desenvolver um } \\
\text { projecto de } \\
\text { sustentabilidade } \\
\text { da iluminação }\end{array}$ & Não existe & $\begin{array}{l}\text { Desenvolvimento } \\
\text { Cartas Energéticas e } \\
\text { estudos técnicos } \\
\text { aplicados a casos } \\
\text { específicos }\end{array}$ & $\begin{array}{c}\text { Agência } \\
\text { Regional de } \\
\text { Energia do } \\
\text { Centro e Baixo } \\
\text { Alentejo }\end{array}$ \\
\hline $\begin{array}{l}\text { Classificação geral } \\
\text { da qualidade da } \\
\text { iluminação no } \\
\text { concelho }\end{array}$ & Boa & $\begin{array}{c}\text { Suficiente } \\
\text { - sustentabilidade } \\
\text { da iluminação } \\
\text { pouco } \\
\text { assegurada }\end{array}$ & $\begin{array}{c}\text { Suficiente } \\
\text {-ineficiência em } \\
\text { alguns locais }\end{array}$ & $\begin{array}{c}\text { Suficiente } \\
\text { - iluminação } \\
\text { desadequada a } \\
\text { alguns locais }\end{array}$ & $\begin{array}{c}\text { Suficiente nas } \\
\text { localidades } \\
\text { interiores e } \\
\text { Boa nos centros } \\
\text { urbanos }\end{array}$ \\
\hline $\begin{array}{l}\text { Promoção ou } \\
\text { participação em } \\
\text { projectos de } \\
\text { iluminação }\end{array}$ & $\begin{array}{l}\text { Vários projectos } \\
\text { associados à } \\
\text { recuperação de } \\
\text { património histórico } \\
\text { e arquitectónico }\end{array}$ & Não & Não & $\begin{array}{l}\text { Sim, associado ao } \\
\text { património } \\
\text { histórico. }\end{array}$ & Não \\
\hline
\end{tabular}

Fonte: Inquérito às autarquias, 2009-2010 - Projecto NOITe

Apesar de, cada vez mais, existir um uso intenso do espaço-tempo da noite, sobretudo nas cidades, onde a concentração de população e actividades é maior, esta tem sido uma temática muito pouco abordada na literatura relativa ao planeamento urbano. Esta situação deve-se em parte à relativamente recente afirmação deste período como um espaço de importância similar ao diurno, pelas características apontadas atrás, e também à visão da noite como um mero prolongamento do dia. Acontece que a noite é um período diferente do dia, não só pelas características naturais (luz solar), mas sobretudo pela representação que esta tem no ser humano, pelos públicos que a usam, e também pelo tipo de actividades que nela existem. A noite carece de um lugar no planeamento urbano, nas agendas políticas. Para tal é essencial diagnosticar as pressões, conflitos e usos, é fundamental caracterizar actividades, utilizadores e espaços nas cidades. Porém, a reflexão e o planeamento sobre a 
noite não indica uma segregação espacial das actividades ou dos lugares com maior dinamismo nocturno. Os espaços planeados da noite, não perdem a sua função durante o dia, pois podem ter actividades adaptadas, com programas que diferem consoante a hora do dia ou actividades que acontecem simultaneamente no mesmo espaço, seja de dia ou de noite. Veja-se o exemplo do estabelecimento comercial localizado junto ao Rio Tejo, em Lisboa, no Cais da Pedra. No mesmo armazém reabilitado, com apontamentos da herança industrial, funciona o cabeleireiro Facto Lab durante o período diurno, e à noite transforma-se para dar lugar à discoteca/bar Odessa, que acolhe também exposições variadas, concertos e demonstrações de arte urbana (http://lazer.publico.pt/artigo.asp?id=257315).

\subsection{Perspectivas francófona e anglo-saxónica sobre o estudo da noite}

Além das abordagens mais frequentes, relacionadas com a iluminação e segurança, existe um importante conjunto de autores que analisam a temática da noite sob a perspectiva da representação, dos usos do tempo e da dimensão cultural e dos lazeres.

Neste contexto, destacam-se sobretudo duas visões: i) uma, levada a cabo por alguns autores francófonos, como por exemplo, Cauquelin (1977); Deleuil (1994); Ascher (1997); Paquot (2000); Gwiazdzinski (2003; 2005), Espinasse (2004; 2005), centram-se numa abordagem da noite sob a perspectiva das vivências nocturnas. Salientam as paisagens urbanas e suas transformações, o papel do planeamento da luz, como forma de diferenciar e valorizar territórios; ii) a outra centra-se na economia da noite como ponto de partida para a resolução de problemas como o alcoolismo ou a criminalidade. Aliada à temática da noite urbana, surgem as questões da segurança e da regulação urbana, por via da análise da segregação espacial à noite, para entender em que medida estas escolhas se reflectem neste espaço-tempo. Os autores anglo-saxónicos tendem a abordar a noite no sentido das políticas de regulação do espaço público à noite (Talbot, 2007; Helms, 2008; ou Pain; Smith, 2008).

Helms (2008), por exemplo centra o seu estudo na segurança dos centros urbanos, mais concretamente de Glasgow, cidade inglesa pós-industrial, onde um dos objectos de estudo é precisamente a noite, na sua dimensão mais propícia para o acontecimento de comportamentos desviantes. Temas como o policiamento, a regulação social, ou o desenvolvimento de medidas especificamente adequadas às actividades e usos do período nocturno, são evidenciados de forma clara, no sentido de prevenir o crime e ordenar a sociedade. As questões da herança do passado industrial e da forma como ele se reflecte no emprego e na sociedade, encontram-se subjacentes à abordagem da temática da noite (fig. 1).

São de destacar as várias iniciativas levadas a cabo pelas autoridades de Glasgow, mencionadas por Helms (2008), que permitiram, desde 1994, regular comportamentos que ocorriam à noite e que inibiam o usufruto do espaço por razões de segurança: City Watch (1994) foi o primeiro passo tomado, assegurando a vigilância do espaço público; Spotlight iniciative (1999) constituiu uma campanha policial para a 
redução do alcoolismo e da violência por ele gerada; Graffiti force (2000) para bairros sem grafittis; Hard Traget Campain to Crack Down on Retail Crime (2000) para a prevenção do crime dirigido aos espaços comerciais, de clientes e trabalhadores; no Glasgow Safer City Center (2002) uma das medidas de segurança para o centro da cidade foi a melhoria da eficiência da iluminação.

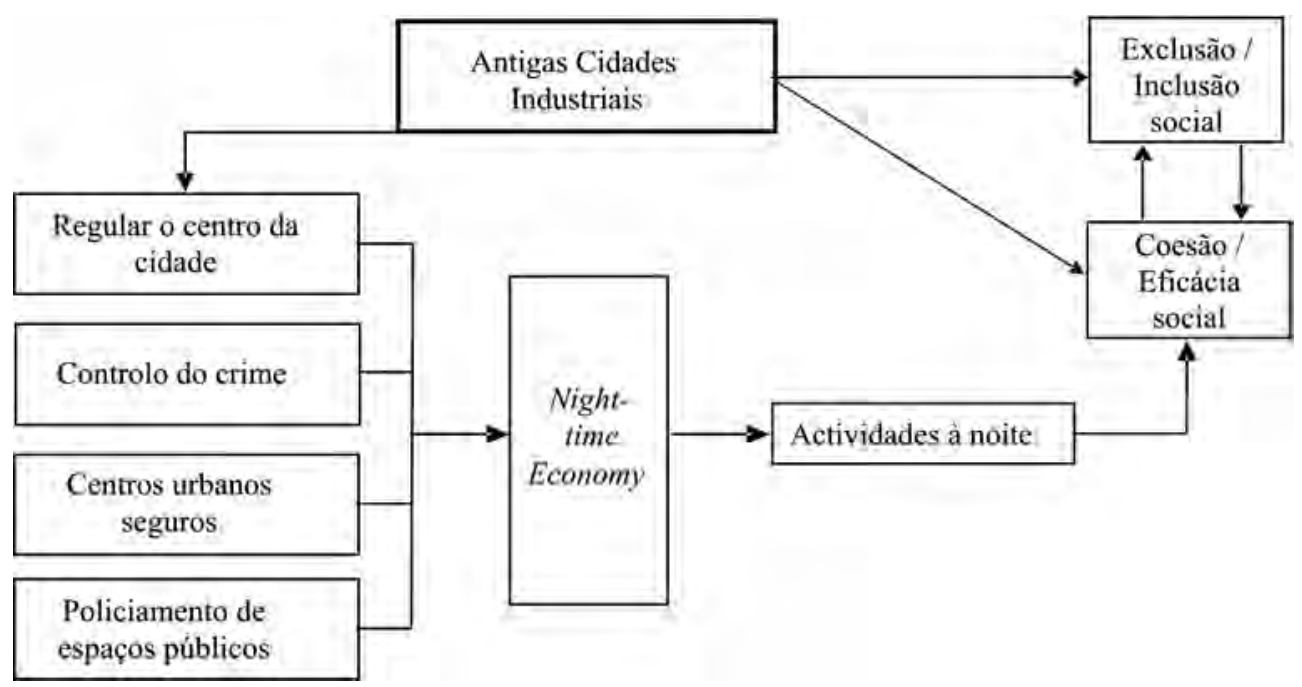

Fig. 1 - Esquema representativo dos temas abordados no trabalho de Helms (2008).

Fig. 1 -Representative scheme of the themes addressed in the Helms (2008) work.

Fonte: baseado em Helms (2008)

O conjunto das actividades culturais, como o cinema, o teatro, a música ou a dança, pertencem ao segmento económico que mais tens crescido associado à noite urbana (Alves, 2010). Nos autores franceses recai a preocupação da espacialização nocturna dessas actividades, dos fluxos que movimentam e do impacto que estas actividades de lazer têm no funcionamento da cidade, que outras economias desenvolvem, e que outras actividades crescem em torno das artes e dos serviços culturais. Estas questões são abordadas, por exemplo por Deleuil (1994), no seu estudo sobre a evolução dos lazeres nocturnos na cidade de Lyon, a partir de 1946, e a relação das pessoas com o espaço da noite, com as actividades. A cidade foi "dividida" em bairros onde foram identificadas as diversas tipologias de lazeres, analisadas licenças de abertura e fecho e ainda calculadas concentrações de população em torno dos estabelecimentos de lazer (à noite). Os espaços, as populações e as práticas nocturnas foram tidas em conta nesta análise, através de entrevistas a vários tipos de público da noite, "Ce sont les personnes à pratiques frequentes/établissements multiples que l'on pourrait appeler noctambules. Mais ce mot n'appartient pas au monde de la nuit, et n'est pas revendiqué, ou très rarement, par les population nocturnes. (...) Cepen- 
Quadro III - Síntese das perspectivas francófonas e anglo-saxónicas do estudo das noites urbanas. Table III - Francophone and anglo-saxon urban night studying perspectives.

\begin{tabular}{|c|c|c|c|c|}
\hline \multicolumn{2}{|c|}{ Autor } & \multirow{2}{*}{$\begin{array}{l}\text { Tema dominante } \\
\text { Economia da } \\
\text { noite }\end{array}$} & \multirow{2}{*}{$\begin{array}{l}\text { Sub-temas e palavras-chave } \\
\text { - nightlife; }\end{array}$} & \multirow{2}{*}{$\begin{array}{l}\text { Citações de destaque / outros exemplos } \\
\text { "specifically, inner city areas began to look at the } \\
\text { potential of cultural forms, such as cultural quarters } \\
\text { and nightlife zones (...), in cities of the North and } \\
\text { London" (p.132) }\end{array}$} \\
\hline 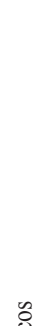 & $\begin{array}{l}\text { Talbot, D., } \\
2007\end{array}$ & & & \\
\hline 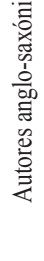 & $\begin{array}{l}\text { Helms, G., } \\
2008\end{array}$ & $\begin{array}{c}\text { Espaços } \\
\text { urbanos }\end{array}$ & $\begin{array}{l}\text { - centro da cidade } \\
\text { - antiga cidade industrial } \\
\text { - espaços públicos / privados } \\
\text { - segurança } \\
\text { - controlo do crime } \\
\text { - policiamento } \\
\text { - night-time economy } \\
\text { - bares, clubes, pubs }\end{array}$ & $\begin{array}{l}\text { "(...) yobbish and disorderly behaviour in British } \\
\text { town centres can often be directly attributed to thriv- } \\
\text { ing night-teime economies which have been exactly } \\
\text { one of those new growth sectors promoted as part of } \\
\text { economic restructuring" (p.93) }\end{array}$ \\
\hline & $\begin{array}{l}\text { Pain, R.; } \\
\text { Smith, S. J. } \\
\text { (eds.), } \\
2008\end{array}$ & Medo & $\begin{array}{l}\text { - medo } \\
\text { - segregação } \\
\text { - raça } \\
\text { - imigrantes } \\
\text { - espaço público } \\
\text { - crime } \\
\text { - geopolítica }\end{array}$ & $\begin{array}{l}\text { "(...) focus on fear, crime and violence almost ex- } \\
\text { clusivey as problemas of public spaces and strang- } \\
\text { ers. Fear is viewed as a problem of city centres, ur- } \\
\text { ban streets and parks, rather than homes, } \\
\text { semi-private spaces (...)"(p.12) }\end{array}$ \\
\hline & $\begin{array}{l}\text { Deleuil, J.M., } \\
1994\end{array}$ & $\begin{array}{l}\text { Actividades } \\
\text { de lazer à noite }\end{array}$ & $\begin{array}{l}\text { - noite } \\
\text { - representação espacial do lazer à noite } \\
\text { - identidade nocturna } \\
\text { - ritmos e fregueses da noite } \\
\text { - frequência semanal/weekend da noite } \\
\text { - segregação e confronto } \\
\text { - espectáculos nocturnos } \\
\text { - mitos urbanos à noite }\end{array}$ & $\begin{array}{l}\text { "Le quartier nocturne est également identifié en } \\
\text { fonction du degré de sociabilité auquel donnent lieu } \\
\text { ses établissements, degré inversement proportionnel } \\
\text { à la perception qu'on a du rôle de l'argent dans la } \\
\text { production du loisir" (p.68). } \\
\text { "(...) la distinction entre fréquentation de semaine et } \\
\text { fréquentation de week-end s'impose (...)" (p.73). }\end{array}$ \\
\hline 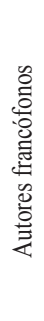 & $\begin{array}{l}\text { Gwiazdzinski } \\
\text { L, 2003, } 2005\end{array}$ & $\begin{array}{l}\text { Paisagens e } \\
\text { ritmos } \\
\text { urbanos }\end{array}$ & $\begin{array}{l}\text { - noite } \\
\text { - ciclo cicardiano } \\
\text { - ritmos de vida urbanos } \\
\text { - "nocturbanas" } \\
\text { - pressões e conflitos } \\
\text { - tempo livre } \\
\text { - tensões sociais } \\
\text { - fronteira dia / noite } \\
\text { - várias noites na "noite" } \\
\text { - serviços } 24 \mathrm{~h} / 24 \mathrm{~h}\end{array}$ & $\begin{array}{l}\text { No coração da noite, entre a } 1 \mathrm{~h} 30 \text { e as } 4 \mathrm{~h} 30 \text {, as dua- } \\
\text { lidades impõem-se: a noite que dorme rivaliza com } \\
\text { a noite que se diverte. Neste horário, a maioria dos } \\
\text { serviços registam as mais baixas taxas de utilização, } \\
\text { ao contrário de actividades nocturnas como bares e } \\
\text { discotecas. As pessoas que deambulam pela cidade } \\
\text { confrontam-se a si e aos outros, criando tensões. O } \\
\text { espaço-tempo da noite é em simultâneo um espaço } \\
\text { de produção imaterial. }\end{array}$ \\
\hline & $\begin{array}{l}\text { Espinasse e } \\
\text { Buhagiar, } \\
2004\end{array}$ & $\begin{array}{l}\text { O público da } \\
\text { noite }\end{array}$ & $\begin{array}{l}\text { - práticas nocturnas } \\
\text { - representações da noite } \\
\text { - sono e calma vs. festa e transgressão } \\
\text { - noite como estilo de vida } \\
\text { - responsabilidades familiares vs. jovens } \\
\text { - práticas culturais à noite } \\
\text { - lazer e recreio }\end{array}$ & $\begin{array}{l}\text { Apesar da carga negativa que se associa à noite, sur- } \\
\text { gem novas representações, que se prendem com a } \\
\text { criatividade e a libertação de comportamento. Os } \\
\text { autores demonstram, através de um inquérito reali- } \\
\text { zado em França, que na perspectiva dos jovens adul- } \\
\text { tos, a noite representa liberdade e, portanto, um } \\
\text { tempo que foi escolhido, ao contrário do dia, ao qual } \\
\text { associam as obrigações e outros constrangimentos. }\end{array}$ \\
\hline
\end{tabular}


dant les pratiques de ces populations sont les plus intéressantes.” (1994: 77). Nos esboços dos lazeres nocturnos em Lyon, o autor caracteriza a sua distribuição por três períodos distintos: a) 1946-1962 neste período o centro da cidade concentra $80 \%$ dos estabelecimentos com licença de funcionamento nocturno, verificando-se que os salões de baile, por exemplo, são o grupo dos lazeres que surgem um pouco mais dispersos na cidade; b) 1962-1973 a área de concentração de estabelecimentos com funcionamento nocturno expande-se em tamanho, surgindo em seu torno outros pontos de lazer. É possível verificar que nos bairros mais periféricos da cidade, começam a aparecer, pontualmente, salas de frequência nocturna (traduzido do francês) e nos bairros envolventes do centro, as licenças de abertura à noite passam a ser de $15 \%$ a $30 \%$; c) 1973-1990, o último período apresentado por Deleuil (1994) mostra a expansão e consolidação dos estabelecimentos que estão abertos durante a noite no centro da cidade, bem como a reprodução do mesmo modelo para os bairros mais periféricos. Dos dez bairros identificados pelo autor, apenas dois possuem, menos de $6 \%$ dos estabelecimentos com licenças nocturnas, cinco deles viram aumentadas em $30 \%$ a possibilidade de estarem abertos à noite, quando comparados com o período anterior. São agora três os bairros com uma forte concentração de lazeres nocturnos, largamente frequentados (Deleuil, 1994: 23; 34; 49).

De forma a sistematizar conteúdos, o quadro que se segue reúne alguns autores que se destacam pelas suas abordagens diversificadas, pertinentes para o estado actual do planeamento das cidades.

\section{A IMPORTÂNCIA DAS ACTIVIDADES DE LAZER À NOITE}

\section{A expansão das actividades económicas no período nocturno}

As actividades económicas relacionadas com os serviços e lazer começam a conhecer uma grande expansão, devido à quebra da indústria produtiva nos centros das cidades. Esta tendia a localizar-se cada vez mais na periferia da cidade, noutra região ou noutros centros de decisão mundiais. Esta lógica obedecia a importantes alterações macroeconómicas na forma de produção e à localização das indústrias, mas também a importantes alterações na estrutura da sociedade, nomeadamente a assunção do individualismo na lógica de consumo, apoiado por uma maior globalização e massificação deste. Maiores níveis de instrução e riqueza requereram outros produtos e experiências, para além do consumo de bens essenciais (Hollands; Chatterton, 2003). O mesmo afirmam Brabazon e Malinder (2007), que identificaram a transição da identidade formada através do trabalho, para a identidade caracterizada pelo consumismo A par destas importantes mudanças, deu-se outra que consubstancia também a afirmação das actividades de lazer, como é o caso do crescimento e desenvolvimento da publicidade e da marca, como factores de associação do consumidor a um determinado produto e estilo de vida, caracterizando fortemente os espaços de lazer (venda de produtos) e os seus utilizadores. Estas mudanças 
tiveram lugar nas últimas três décadas, que foram caracterizadas ao nível do planeamento e crescimento urbanos por uma rápida transição das cidades como locais de produção e organização racional, para locais para viver, trabalhar e entreter. Pode assim observar-se que o crescimento das actividades de lazer é paralelo a esta mudança, sendo exponencial o seu crescimento no sentido do paradigma da cidade como espaço de entretenimento, vivência e cultura.

O grande crescimento das actividades económicas no período nocturno aconteceu sobretudo na década de 90, apoiado pelos poderes municipais, com o aparecimento de inúmeras actividades de lazer. O objectivo das cidades, era expandir progressivamente as actividades culturais e de lazer para um período até aí muito pouco utilizado, assim como voltar a povoar os seus centros e aí afirmarem-se como pólos activos económica e culturalmente. Tendencialmente, a expansão destas actividades de lazer foi crescendo em núcleos, e não de uma forma disseminada, núcleos esses que, ou apresentavam uma tendência histórica de uso nocturno do espaço (vejam-se os casos de Times Square em Nova Iorque ou Bairro Alto em Lisboa), ou então em novas zonas de lazer que surgiam no seguimento de uma nova zona funcional da cidade, resultante de processos de renovação, requalificação, nobilitação entre outros (caso do Parque das Nações em Lisboa ou das Docklands em Londres). Assim, as cidades tentavam modernizar a sua imagem, combatendo simultaneamente alguns problemas como a criminalidade, associados ao esvaziamento de certas zonas.

Em Inglaterra a regeneração dos centros urbanos, associada a uma componente nocturna, conheceu uma expressão mais precoce. Este crescimento deu-se devido ao surgimento do pensamento das cidades como sítios inclusivos, que promovem a igualdade e o desenvolvimento das zonas mais pobres dos centros históricos, devendo estes objectivos ser suportados pela aposta no crescimento das actividades de lazer e culturais. Para isso foram simplificadas as leis de construção e laboração durante o período nocturno e foram estabelecidas várias parcerias entre os municípios e os agentes privados (Roberts, 2004).

Aspectos positivos da expansão das actividades de lazer nos centros históricos centraram-se na recuperação de vários edifícios históricos, assim como na requalificação de edifícios que eram usados para outras actividades. Adicionalmente, os edifícios de uso anteriormente industrial, ou em situação de abandono, merecem o mérito da revitalização, contribuindo para a repopulação de zonas anteriormente vazias.

O crescimento exponencial das actividades de lazer e cultura, associado a uma população que cada vez mais, usa este tipo de actividades, conduziu também ao aumento do número de pessoas que trabalham à noite. Desta forma, as cidades ganham uma nova dinâmica, o que levou a uma diferenciação cada vez maior entre o período diurno e nocturno. Esta polarização alerta para um conjunto de questões, que podem ser abordadas como desafios, que se centram em temas como as maneiras formais e informais de controlo urbano, empreendedorismo corporativo e privado simbolizado através de economias mainstream e de nicho, assim como o papel da governância a uma escala micro, tudo isto assente na respectiva articulação com as políticas ao nível nacional, regional e local. 


\section{Caracterização das actividades de lazer à noite e sua relação com o turismo}

Não só as actividades de lazer e turismo são cada vez mais significativas no contexto da economia mundial, como apresentam no período nocturno importância fulcral, pela sua representatividade, mas também pela forma como estruturam a economia da noite: "[...] a hospitalidade (alojamento), turismo e comércio são as áreas de crescimento da economia (actual), providenciando a base e enquadramento da economia nocturna" (Hollands; Chatterton, 2003).

A "economia da noite", associada ao lazer e à cultura, criou uma classe de trabalhadores que não se rege pelas normas fordistas e pelos horários diurnos, é segundo Richard Florida (Hollands; Chatterton, 2003) a "classe criativa" que,segundo este, compõe cerca de um terço da força de trabalho e inclui pessoas que trabalham em design, tecnologia da informação, educação, música, arquitectura e outras artes, mas também em serviços como restauração, limpeza, call centers. A verdadeira mudança reside na não predefinição de um horário, sobretudo à noite, podendo este ser acomodado consoante as necessidades da pessoa. Em termos remuneratórios, as diferenças tendem a ser maiores que no horário diurno, pois os trabalhadores tendem a ser significativamente mal pagos, ou recebem de acordo com a taxa de trabalho nocturno.

Ao contrário da procura turística nas áreas rurais, onde o turismo começou por estar essencialmente vocacionado para as questões de saúde, evoluindo para o bemestar e a necessidade de recreação (Baschleitner, 1999; Saxena et al., 2007), o lazer à noite nas cidades tende a ser efémero, pontual, ritualizado e eufórico e gera uma economia muito dinâmica. A atractividade turística da noite nas cidades é para Queige (2005), o futuro. Tendencialmente os lazeres nocturnos vão ganhando espaço nas cidades, emergindo novas programações que marcam o estado da cultura e do lazer, as inovações e as modas associadas ao turismo de short-breaks, estando incluído nestes "pacotes" o turismo de negócios e de conferências, com idas a espectáculos, mas também a restaurantes e bares. De facto, muitas cidades têm a noite como uma das suas principais valências turísticas nas suas imagens de promoção - veja-se o caso de Nova Iorque, Londres ou Paris, que muitas vezes recorrem a campanhas que aludem precisamente à sua beleza nocturna. Associada a esta beleza estão vários produtos turísticos e itinerários associados a um conjunto de actividades de lazer. Por um lado as actividades relacionadas com a restauração, como restaurantes, cafés, bares, por outro, actividades ligadas ao espectáculo, como salas de concerto, teatros, cinemas e actividades de lazer ao ar livre, como festivais de música, feiras, entre outros.

Como demonstra Alves (2010), a oferta dos lazeres nocturnos tende agora a expandir-se devido à crescente abertura de equipamentos culturais, que funcionam também à noite, e também ao investimento em eventos que marquem as tendências de luz, cor e arte na cidade, como os festivais de luz que cada vez mais ocorrem em mais cidades, sendo exemplos as Nuit Blanches, em Paris, Roma, S. Peterburgo, 
Montreal ou Gaza; a Fête des Lumiérs, em Lyon (França); o Enlightenment, em Durham (Reino Unido); LuzBoa, em Lisboa (Portugal), arrastando multidões de visitantes e dinamizando a economia regional (Alves 2007; Almeida e Alves, 2009). À medida que a capacidade de criar novas paisagens nocturnas cresce, geram-se celebrações em torno da luz que atraem visitantes e colocam as cidades e as regiões em redes e circuitos internacionais, com paisagens únicas, diferentes das que podem ser observadas de dia, interferindo com o modo como se vive e se percepciona a cidade.

Um destes casos relacionados com festivais é o de Brighton \& Hove no Reino Unido, onde o município estabeleceu uma politica de afirmação dos festivais que aí eram realizados, através da aposta nas actividades de lazer nocturnas. É o oitavo destino turístico mais popular no Reino Unido, atraindo 8 milhões de visitantes por ano, e facturando mais de 400 milhões de libras. Os festivais e outros eventos similares, organizados sobretudo ao ar livre, são componentes bastante importantes na atractividade da cidade, sendo os eventos nocturnos o principal elemento de atracção turística. Assim, o objectivo do município era o de reduzir a burocracia para obtenção de licenças de operação para actividades de lazer ao ar livre englobadas nos festivais, assim como reduzir as queixas de ruído, bem como uma melhor gestão da grande quantidade de visitantes que chegam num curto espaço de tempo. Foram assim definidas funções para cada agente com responsabilidade no festival:

Quadro IV - Funções e responsabilidades do pessoal ao serviço no festival de Brighton \& Hove.

Table IV - Tasks and responsibilities' of the staff during the Brighton \& Hove festival.

\begin{tabular}{l|l}
\hline Organização / papel desempenhado & \multicolumn{1}{c}{ O que foi feito } \\
\hline $\begin{array}{l}\text { Líder do Conselho e Membros do } \\
\text { Gabinete }\end{array}$ & $\begin{array}{l}\text { Papel de liderança, tornar reconhecida a importância de festivais e eventos para } \\
\text { a cidade, promovendo o seu desenvolvimento. }\end{array}$ \\
\hline $\begin{array}{l}\text { Câmara Municipal de Brighton } \\
\text { \& Hove; }\end{array}$ & $\begin{array}{l}\text { Trabalho de equipa, no sentido de amenizar os conflitos e apoiar os organizadores } \\
\text { de eventos; }\end{array}$ \\
$\begin{array}{l}\text { Equipa de Licenciamento; } \\
\text { Equipa de Eventos; }\end{array}$ & $\begin{array}{l}\text { Continuar a desenvolver trabalhos em parceria - para mais informações ver } \\
\text { abaixo; }\end{array}$ \\
$\begin{array}{l}\text { Equipa de Saúde Ambiental; } \\
\text { Equipa de Planeamento de }\end{array}$ & $\begin{array}{l}\text { Melhoramento de relações entre os organizadores e inclusão de boas práticas de } \\
\text { trabalho nas estratégias futuras. }\end{array}$ \\
$\begin{array}{l}\text { Emergência; } \\
\text { Equipa de Artes }\end{array}$ & $\begin{array}{l}\text { Continuar a desenvolver trabalhos em parceria - para mais informações ver } \\
\text { abaixo. }\end{array}$ \\
\hline Polícia de Sussex & $\begin{array}{l}\text { Usar a frequência de rádio para manter as unidades policiais em alerta durante o } \\
\text { evento. }\end{array}$ \\
\hline $\begin{array}{l}\text { Parceria com o Gabinete de Reduçãa } \\
\text { da Criminalidade }\end{array}$ &
\end{tabular}

Fonte: Brighton \& Hove City Council (2009), tradução dos autores

Foram licenciados todos os parques e jardins situados no local do festival, de forma a ser mais simples para os organizadores do evento atraírem e organizarem as tipologias de actividades presentes. Juntamente com esta iniciativa foi criado um 
recinto cultural, apoiado por uma zona de comida e bebida, assim como iluminação específica para destacar locais com características diferentes. Foram criados calendários a serem divulgados pelos organizadores com os timings necessários para cumprir a legislação em vigor, assim como equipas com elementos da polícia, do município e da comissão organizadora, para monitorizarem dia a dia o festival. Foram promovidas reuniões entre a população e os organizadores, de forma a encontrar soluções consensuais relativamente ao uso do espaço e horários de ruído,; foram ainda organizadas equipas de limpeza, preparadas para agir assim que o evento terminasse.

Os resultados destas acções são positivos. No presente o município de Brighton \& Hove organiza mais de 60 festivais por ano. Alguns ensinamentos foram também retirados, nomeadamente: a redução de licenças aponta para melhor eficácia dos serviços e cria relações mais duradouras entre as actividades participantes e o poder local; para cada evento de larga escala, é dedicada uma equipa de parceiros, que trabalha conjuntamente para melhorar a segurança e controlar multidões; é desenvolvido bastante trabalho com os organizadores antes do evento, como forma de reduzir ao máximo as necessidades de planeamento durante o evento, deixando este tempo livre para as questões práticas; a relação entre a polícia e a organização melhorou substancialmente. O exemplo deste festival aponta para a importância fulcral, sobretudo para municípios de dimensão média ou pequena, da existência de eventos que atraiam população, divulgando assim características locais únicas e estimulando um conjunto de actividades económicas relacionadas com o evento. A acompanhar estes eventos pontuais, devem também ser tidas em conta políticas que incidam no quotidiano, na potencialização de espaços que já possuem um uso nocturno associado a fins turísticos, mas também na criação e apoio a novos espaços turísticos nocturnos, que potenciem sinergias locais únicas, aliando tradição, modernidade e inovação, constituindo-se assim produtos turísticos de valor singular. Estes espaços podem constituir elementos essenciais para a economia local numa primeira fase e, se planeados de forma integrada, virem a ser um dos pilares do desenvolvimento económico do território em questão, necessitando para isso de um planeamento integrador que junte, na óptica da acção, residentes, comerciantes, artistas e planeadores.

\section{DISCUSSÃO}

Os problemas da expansão das actividades de lazer à noite estão bastante relacionados com o aumento exponencial do consumo de álcool nestas zonas da cidade, assim como com a violência potencialmente associada a este fenómeno. Outros problemas estão associados ao ruído, sobretudo para a população residente na área, assim como a ocupação massiva e pontual de determinado espaço, que leva à sobrelotação deste e sobredimensionamento dos espaços que muitas vezes não estão adequados ao seu uso diurno. 
Num inquérito nacional realizado aquando do estudo "Good Practice in Managing the Evening and Late Night Economy: A Literature Review from an Environmental Perspective" (Roberts, 2004) foi perguntado às pessoas, quais os maiores problemas relacionados com a noite nos locais onde viviam. Apesar de o estudo dar um grande enfoque à problemática do álcool, relacionando-o de forma forçada com os factores apontados, é claro, e também demonstrado no próprio texto, que muitas vezes criam-se ideias preconcebidas acerca da noite, dando-se valor a certos problemas que, em muitos casos, não são os mais graves em determinada contexto, mas sim os mais mediáticos e mais visíveis no dia-a-dia. Assim, foram apontados os seguintes problemas como os mais graves (por ordem decrescente de importância): falta de transporte público (52,8\%); lixo nas ruas $(33,7 \%)$; má conduta $(30,3 \%)$; sentimento de insegurança/ameaça $(29,2 \%)$; ruído $(28,1 \%)$; violência entre grupos (23,6\%); vandalismo (15,7\%); tráfico de droga $(13,6 \%)$.

Outro dos problemas associados à noite, encontra-se relacionado com o monopólio das actividades de lazer por parte de um pequeno grupo de empresas e marcas, associados à desigualdade de acesso e à segmentação de mercado. Neste caso, o expoente máximo são as zonas de lazer para as classes mais abastadas, onde se tenta minimizar ao máximo o risco e a insegurança mas, ao mesmo tempo, recriar este tipo de atmosfera. Estas têm sido geradas em zonas anteriormente pobres, criando uma autoexclusão de certos grupos populacionais. Aqui entram conceitos muito importantes como o da higienização, estilização e nobilitação (Hollands; Chatterton, 2003). É possível observar, em parte, este fenómeno em certas zonas de Lisboa como o Bairro Alto, Alcântara e o Parque das Nações, e todas as tensões que por vezes aqui são criadas.

A resposta a estes problemas, no caso do Reino Unido, surgiu através da Lei do Licenciamento de 2003, que previu uma maior responsabilização por parte do poder local na atribuição e gestão das licenças, passando estas a ter uma gestão mais precisa, responsabilizando-os por definir a política de licenciamento no seu espaço de influência. Esta política de licenciamento deve cumprir 4 objectivos específicos: prevenção do crime e desordem; segurança pública; comportamentos desviantes; protecção das crianças. Quanto ao horário de funcionamento das actividades de lazer ficasegundo esta lei, ao critério de cada estabelecimento, sendo a crença dos políticos que este factor dê lugar a uma auto-regulação e, consequentemente, a diferentes períodos de encerramento, o que conduziria a uma menor concentração de população.

Uma das propostas de planeamento dos espaços e das actividades predominantemente nocturnas assenta precisamente no conhecimento da realidade, de forma a melhor decidir e intervir sobre ela. Como instrumento metodológico proposto, tem vindo a ser desenvolvido desde 2008, o Projecto NOITe: Oportunidades e Inovação no Território, com o objectivo de estudar a noite urbana como uma diversidade de funções e múltiplas práticas sociais e culturais. Pretende compreender as relações económicas e políticas resultantes de novos ritmos da sociedade contemporânea e contribuir para uma nova visão de planeamento territorial, para que os espaços públicos urbanos possam "viver" 24 horas. As dimensões de análise do projecto foram definidas como sendo as pessoas, ou seja, os utilizadores da noite, as actividades 
nocturnas, e as câmaras municipais. Para responder a perguntas como: Serão as relações económicas, sociais e políticas, que se desenvolvem sobretudo durante a noite uma mera continuação das relações diárias, ou assumirão formas específicas? Será a evolução da noite e suas funções unicamente resultado da oferta e procura? Como contribuem os mitos e representações culturais da noite para tal evolução? Como é que o projecto NOITe pode marcar a diferença na forma como a noite é estudada? Que políticas públicas devem ser seguidas? Como é que a arte, em particular a arte de iluminação, pode revitalizar a vida nocturna e o espaço urbano? Foram utilizadas as metodologias de inquéritos semi dirigidos e fechados, entrevistas dirigidas e abertas no que diz respeito aos responsáveis pela iluminação e animação nocturna das autarquias locais. As actividades de lazer à noite afiguram-se como um dos elementos centrais da investigação levada a cabo no âmbito do projecto, pelo que foi necessário desenvolver uma metodologia que integre uma abordagem única e que permita aos planeadores e decisores fazer as melhores escolhas para o espaço em questão.

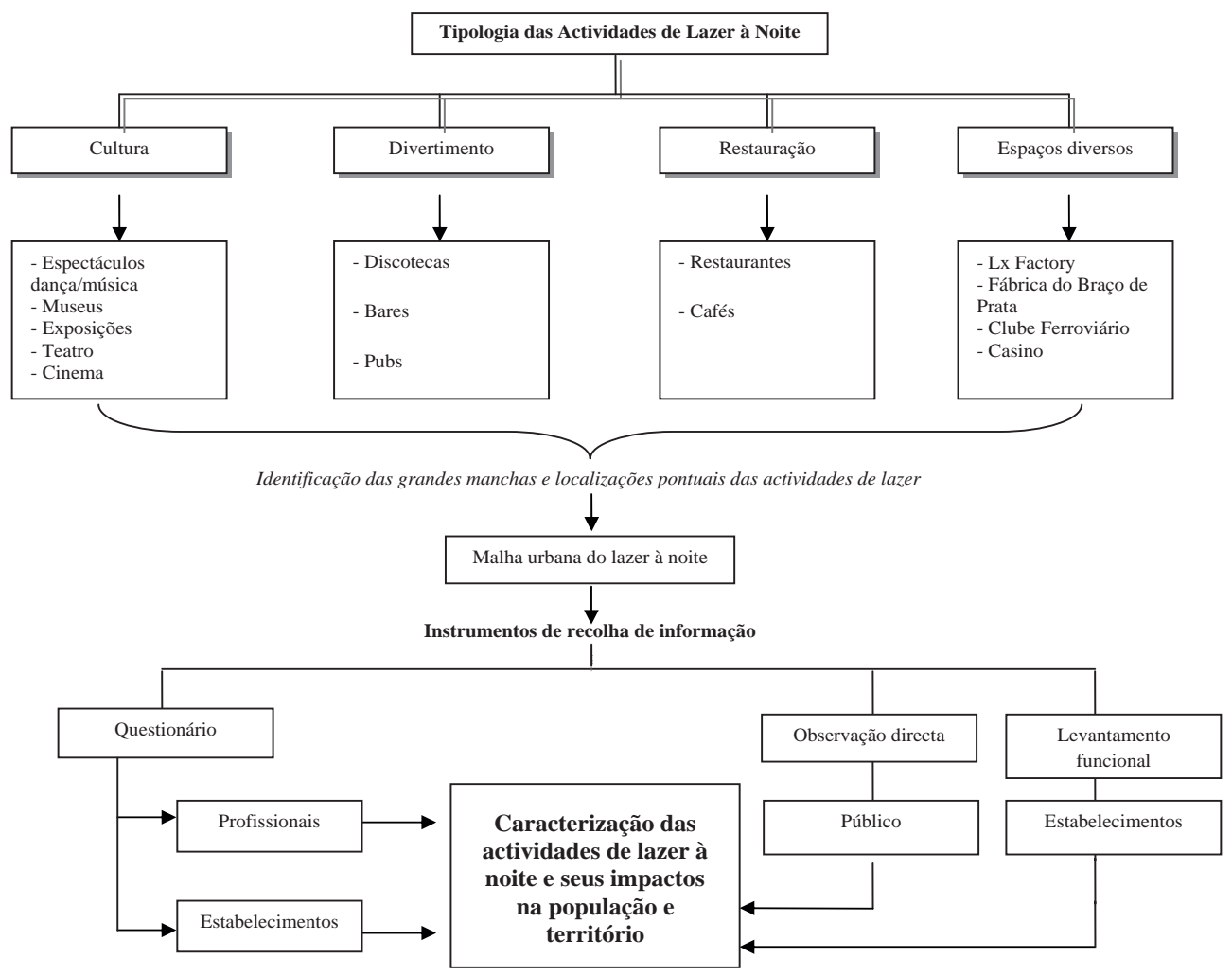

Fig. 2 - Esquema de análise a ser adoptado pelo Projecto NOITe para o estudo das actividades de lazer à noite.

Fig. 2 - Analysis scheme to be adopted by the Project NOITe for the study of leisure activities at night. 
Este modelo apresenta vantagens e inconvenientes. Destaca-se como vantagem a definição de tipologias que, apesar de variarem de autor para autor, permitem balizar os tipos de actividades de lazer existentes. Contudo, esta é uma das maiores dificuldades no corpo teórico de textos sobre esta problemática: a definição de actividades de lazer, assim como a definição de tipos de actividades. Desta forma, com este modelo pretendeu-se contribuir com uma nova visão sobre a organização das actividades de lazer. Havendo uma definição categórica de organização destas, o objecto de análise poder ser estudado de forma mais clara. Outro desafio é a escolha de áreas urbanas de lazer, mais precisamente a sua delimitação, que nem sempre é bem definida, assim como a obtenção e sistematização da informação a recolher.

As vantagens da aplicação deste método residem na sistematização dos profissionais da noite, por tipologia de actividade de lazer e a sua aplicação directa ao território, visto o agrupamento das actividades de lazer possuir uma componente espacial. Nesta perspectiva, destaca-se a possibilidade de identificar as actividades de lazer por localização e entender a sua forma de organização, pois, ao mesmo tempo que se identificam os trabalhadores, identificam-se também os próprios estabelecimentos. A partir desta informação podem-se extrapolar e propor áreas de lazer nocturnas até aqui não identificadas como tais, definir ritmos de ocupação por tipologia de actividade e, até, prever formas de crescimento e ocupação de determinadas actividades no território, podendo assim este modelo vir a ser útil, a nível científico, para a percepção da importância e desenvolvimento do lazer em zonas urbanas, e de uma forma mais empírica útil para os agentes que intervêm no território com funções de regulação.

\section{CONCLUSÕES}

Sem dúvida que a noite, é um espaço-tempo de extrema importância na vida das cidades, sobretudo no que respeita às actividades de lazer e turismo que a estas está associado. As inovações na iluminação, a par das importantes mudanças na organização da economia, assim como alterações profundas na sociedade e na cultura, conduziram a um crescimento acelerado das actividades de lazer desde o princípio do século XX, mas sobretudo na sua última metade. A noite constitui, neste contexto, o "escape" do dia, sendo o período eleito para a diversão, socialização e descanso. Por outro lado, não se pode esquecer o número exponencial de pessoas que trabalham em diversas actividades à noite e que também contribuem para o funcionamento dos lazeres. Como afirma Paquot (2000) "Os limites da noite são difíceis de estabelecer pois podem ter diferentes naturezas e variam conforme os lugares, as culturas e a sensibilidade pessoal.". Assim, é interessante verificar que, conforme o enquadramento das problemáticas nocturnas, os diferentes autores francófonos e anglo-saxónicos, abordam a temática da noite, sob prismas totalmente distantes.

A noite assume-se como um produto turístico contemporâneo, cosmopolita, capaz de atrair visitantes e de descriminar positivamente territórios. A existência de 
várias "noites" é uma mais-valia para o estudo do próprio objecto, permitindo destacar rituais, padrões, áreas privilegiadas, zonas de trabalho, zonas de lazer, fluxos de turismo, actividades predominantes, entre outros.

No exemplo dado sobre o município de Brighton \& Hove, no Reino Unido, é notória a importância das actividades de lazer, no caso específico dos festivais, para a afirmação de um município, da sua identidade e valores, mas também para o seu crescimento económico, pelas receitas que são geradas. Assim, cada vez mais o lazer associado ao turismo é um elemento central que não deve ser negligenciado pelos poderes locais, pela capacidade única que tem de exposição a outros públicos, mas também pelas possibilidades de reabilitação de certas zonas e de criação de novas zonas; no fundo, de desenvolvimento urbano de uma forma lata.

Realizando-se uma boa parte das actividades de lazer durante a noite, torna-se pertinente perceber as suas dinâmicas e a sua importância. A proposta de uma metodologia que visa a definição de tipologias de actividades de lazer nocturnas, e o seu estudo através de vários instrumentos de análise, com vista a melhor caracterizar a sua distribuição espacial e os públicos-alvo, assim como a caracterização dos trabalhadores que aí exercem a sua profissão, acrescenta valor aos estudos até agora realizados. O facto de esta metodologia poder ser aplicada a outras escalas de análise, como o bairro, a freguesia, o concelho ou a região, permite alargar o leque de respostas por parte dos decisores, relativamente a questões como a criminalidade ou o alcoolismo, e também repensar o próprio planeamento de actividades, nos estabelecimentos ou nos espaços públicos.

\section{BIBLIOGRAFIA}

Alves T (2010) Geografia da Noite: conhecer, compreender e repensar o território. TERiTUR, CEG, Universidade de Lisboa, Lisboa.

Alves T (2008) Noite e turismo: novas oportunidades para a inovação no território Turismo, inovação e desenvolvimento: Actas do I Seminário Turismo e Planeamento do Território. Lisboa, CEG: 175-186.

Alves T (2007a) A noite, a cidade e a geografia das actividades económicas. In Centro de Estudos Geográficos (Ed.) Geophilia. O sentir e os sentidos da Geografia. Homenagem a Jorge Gaspar, Lisboa: 498-500.

Alves T (2007b) Art, light and landscape new agendas for urban development. European Planning Studies, 15(9): 1247-1260.

Alves T, Almeida D (2009) Planning the night light as a central issue. RSA Annual Conference - Understanding and Shaping Regions: Spatial, Social and Economic Futures, Leuven, Belgium, Abril, [Acedido em 10 Julho de
2010] http://www.regional-studies-assoc.ac. uk/events/2009/apr-leuven/papers/Alves.pdf

Ascher F (1997) Du vivre en juste à temps au chrono-urbanisme. Les Annales de La Recherche Urbaine, 77:113-122.

Baschleitner R, Zins H A (1999) Cultural tourism in rural communities: the residents' perspective. Journal of Business Research, 4:199-209.

Brabazon T, Mallind S (2007) Into the night-time economy: work, leisure, urbanity and the creative industries. Nebula, 4(3): 161-178.

Brighton \& Hove City Council (2009) Supporting and encouraging well managed festivals and events in Brighton \& Hove [Acedido em 12 de Julho de 2010]. http://www.brighton-hove. gov.uk/

Cauquelin A (1977) La ville la nuit. Paris: PUF.

City of Brighton \& Hove (2008) A partnership approach to the night-time economy. PtP Case Study Brighton \& Hove, Shared Intelligence, London [Acedido em 12 de Julho de 2010]. 
http://www.brighton-hove.gov.uk/index. cfm?request $=\mathrm{c} 1207200$

Deleuil JM (1994) Lyon la nuit, lieux, pratiques et images. Transversales Presses Universitaires de Lyon.

Espinasse C, Buhagiar P (2004) Les passagers de la nuit. Vie nocturne des jeunes. Editions L'Harmattan, Paris.

Espinasse C, Gwiazdzinski L, Heurgon L (coord.) (2005) La nuit en question(s). Editions l'Aube, Paris.

Gwiazidzinski L (2005) La nuit, derniére frontiére de la ville. L'aube essai, Paris.

Gwiazidzinski L (2003) La ville 24 heures sur 24. Editions l'Aube, Collection Monde en Cours, Paris, France.

Helms G (2008) Towards safe city centres? Remaking the spaces of an Old-Industrial City. Hampshire, ed. Ashgate.

Hollands R, Chatterton P (2003) Producing nightlife in the new urban entertainment economy: corporatisation, branding and market segmentation. International Journal of Urban and Regional Research, 27(2): 361-385.

Mizon B (2002) Light pollution: responses and remedies. Springer, London.

Narboni R (2003) Brève histoire de l'urbanisme lumière. In Villette (Eds) Penser la ville par la lumière. Project Urbain, Paris.

Pain R, Smith S J (eds.) (2008) Fear: critical geopolitics and everyday life. collection Re-materialising Cultural Geography, Ashgate.
Paquot T (2000) Le sentiment de la nuit urbaine aux XIX et XX siècles, PUCA. Les Annales de la Recherche Urbaine, 87.

Portela C (2007) Light and architecture. Conference StarLight: a common heritage, Starlight Initiative, Instituto de Astrofísica de Canarias (IAC): 111-114.

Queige (2005) Les rapports entre la nuit et l'attractivité touristique des villes. In Espinasse et al., (Eds) La nuit en question(s). Ed. l'Aube, Paris: 1-18.

Roberts M (2004) Good practice in managing the evening and late night economy: a literature review from an environmental perspective. Office of the Deputy Prime Minister, Central Cities Institute University of Westminster: 21-34.

Saxena G, Clark G, Oliver T, Ilbery B (2007) Conceptualizing integrated rural tourism. Tourism Geographies, 9(4): 347-370.

Talbot D (2007) Regulating the night. Race, culture and exclusion in the making of the night-time economy. Ashgate, Hampshire.

Ville de Lyon (2010) Le Nouveau Plan Lumiére, Lyon Confluence: Schéma des principles de mise en lumière. [Acedido em 12 de Julho de 2010], http://www.lumieres.lyon.fr/lumieres/ sections/en/lyon_and_light/lyon the city specializing_in_ligh; http://www.lyon.fr/vdl/ sections/fr/urbanisme/plan_lumiere_1/le_ nouveau_plan_lumi8409. 